\title{
Estimating Typhoon-Induced Sea Surface Cooling Based upon Satellite Observations
}

\author{
Dan Song ${ }^{1,2}{ }^{\circledR}$, Lulu Xiang ${ }^{1}$, Linghui Guo ${ }^{1}$ and $\mathrm{Bo} \mathrm{Li}^{3, *}$ \\ 1 Institute of Physical Oceanography and Remote Sensing, Ocean College, Zhejiang University, \\ Zhoushan 316021, China; dsong@zju.edu.cn (D.S.); 21834010@zju.edu.cn (L.X.); linghguo@163.com (L.G.) \\ 2 Key Laboratory of Ocean Observation-Imaging Testbed of Zhejiang Province, Zhoushan 316021, China \\ 3 Department of Oceanography, College of Marine Science and Technology, Zhejiang Ocean University, \\ Zhoushan 316022, China \\ * Correspondence: acelibo@zjou.edu.cn
}

Received: 10 September 2020; Accepted: 27 October 2020; Published: 1 November 2020

\begin{abstract}
Typhoons frequently occur in the summer in the northwestern Pacific Ocean, and the responses of the upper ocean to typhoons have drawn extensive attention for decades. In the present work, a modified grid-based maximum response (GMR) method was proposed to estimate the sea surface cooling (SSC) caused by typhoons. The current algorithm (CA) is different from the original GMR method mainly in two aspects: (1) it uses a 5 day average rather than a 2 day average of the sea surface temperature (SST) before the typhoon as the reference temperature; (2) it modifies the fixed radius of $400 \mathrm{~km}$ to the level-7 Beaufort scale wind-force $(\sim 17.1 \mathrm{~m} / \mathrm{s})$ radius to determine the area where the SSC should be calculated. Then the MW-IR OISST data derived from satellite observations were used to compare the SSC estimated by different algorithms in four typhoon cases, Megi, LionRock, Trami and KongRey. The results show that, in all cases, maximum response methods have approached similar results, while the others seemed to have underestimated the SSC in degrees. In the slow-moving LionRock case, grid-based methods were found to have better performance, while in the successive typhoon cases, Trami and KongRey, CA showed an improved result in representing the pre-existing sea surface status before the typhoon KongRey by using the pentad mean SST as the reference temperature. In addition, the use of level-7 wind-force coverage made the results much livelier. In a word, the algorithm proposed here is valid in general. It has advantages in estimating the SSC caused by both slow-moving typhoons and successive typhoons, and should be further applied to related research.
\end{abstract}

Keywords: sea surface cooling; grid-based method; maximum response; slow-moving typhoons; successive typhoons

\section{Introduction}

Tropical cyclones are some of the most severe natural disasters. They have great destructive power and usually bring strong winds, heavy rain, huge waves, and storm surges to coastal areas. The tropical cyclones generated in the northwestern Pacific Ocean (NWPO) often have a long period of air-sea interaction before making landfall, which can easily strengthen them to form so-called typhoons. In other words, the NWPO environment is conducive to the generation and development of strong tropical cyclones [1]. Some recent studies have shown that the ratio of strong typhoons to weak ones happening in the NWPO is slowly increasing due to global warming [2]. Taking China as an example, it has an average of nine tropical cyclones per year in its coastal regions [2,3], causing severe economic losses and casualties. Having a comprehensive understanding of the air-sea interactions 
during typhoons may improve our typhoon monitoring and early warning capabilities to help reduce associated damage [4].

The response of the upper ocean to a typhoon's passage has been a hot issue since the 1980s $[5,6]$. Two remarkable aspects have been suggested as responses to a typhoon's wind force $[7,8]:(1)$ the strengthening and changes in direction of sea surface flow, and (2) the reduction in the sea surface temperature (SST) due to strong vertical mixing. An SST drop is the most obvious feature of the upper ocean's response to a typhoon, and it can easily be measured by means of remote satellite sensing. Researchers found that the SST reduction caused by typhoon transit could vary from 1 to $9{ }^{\circ} \mathrm{C}$ [9-13]. Dare et al. [14] used SST data from 1981 to 2008 to study SST changes in response to global typhoons and found that the largest decreases in SST mostly occurred within one day of typhoon transit in the affected area. They further found that the SST would recover to $44 \%$ of its original climatic state within 5 days and $88 \%$ within 30 days. It was found that the intensity and speed of a typhoon affect the range and recovery time of the SST response. The greater the typhoon intensity and the slower the movement speed is, the stronger the vertical pumping and mixing effect is and, therefore, the greater the temperature drop is [14-17]. When a typhoon is moving at a slow speed, the strength and speed of the typhoon affect the SST cooling, while the temperature drop caused by the rapid movement of a typhoon is mainly controlled by its strength [5]. Song et al. [18] also found that a relatively lower sea level (or cold core eddy) favors causing intense sea surface cooling (SSC) through the study of five strong and super typhoons in 2016. There is a noticeable asymmetry in the cooling path caused by a typhoon. Due to the resonance effect between the local wind and the near-inertial flow on the right side of the typhoon track in the northern hemisphere, the cooling rate on the right side is larger than that on the left side [3,5,19-23]. Xu [24] and others used statistical analysis to study SST changes due to the influence of typhoons in the NWPO from 2000 to 2005. Statistics show that in the sea area and time-period under study, the general situation of typhoon-induced cooling is that the SST on the day of the typhoon's transit decreases the most. On the second and third days of transit, the SST will continue to decrease and reach a minimum, after which the temperature will slowly rise. Liu et al. [25] analyzed the response of the upper ocean to the passage of tropical cyclones using Argo buoy observation data from 2001 to 2004 and found that the deepening of the mixed layer and the decrease in temperature were most obvious within 5 days of the typhoon passing. Park et al. and Wang et al. [26,27] studied the Argo observation data in the North Pacific Ocean from 1996 to 2012 and found that the recovery time of the SST was about 5 to 20 days. The shallow surface layer (about $10 \mathrm{~m}$ ) can quickly recover to its state before the typhoon's transit, but the response of the near-surface layer lasts longer. Recently, Zhang et al. [28] studied the relationship between cold wake size and the storm size, which highlighted the importance of cold wake size in evaluating the power dissipation and ocean heat uptake.

Precise estimation of the SSC is required for statistical analysis to understand the responses of the upper ocean to the typhoon's wind-force and translation speed, as well as the pre-existing sea surface status. It may further be applied to estimate the heat-flux through the air-sea surface to improve coupled numerical models. Generally, the SSC can be recognized as the difference between a minimum temperature (MT) caused by a typhoon and a reference temperature (RT) before the typhoon's arrival. Thus, the divergences remain in how to define the MT and RT. Here listed four main algorithms used by the former researchers:

A1 The SST of the first day after the typhoon's passage (MT) minus that of the day before the typhoon's arrival (RT) [5,29-31];

A2 The minimum SST during the typhoon's passage (MT) minus the average SST over three days before the typhoon's arrival (RT) [32];

A3 The SST averaged over $24 \mathrm{~h}$ to four days after the typhoon passage (MT) minus the SST averaged during 10 to 3 days before the typhoon's arrival (RT) [33]; 
A4 The so-called grid-based maximum response (GMR) method, which treats the average SST 2 days before the initial forcing time as RT and the minimum SST from the arrival to 5 days after the terminal forcing time as MT [34]. Hereafter, this will also be referred to as the LI method;

Many researchers also analyzed and compared the daily SST changes during typhoons instead of calculating the SSC [35-37]. Despite the importance of the sea surface response to typhoons, few papers have discussed the algorithm to estimate the SSC, whose aspects have not been illustrated and studied in detail till now. Therefore, a modified GMR method is proposed by the present work. It will be described along with the data used in this study in Section 2. In Section 3, comparison with the four abovementioned algorithms will be shown. Section 4 contains a detailed discussion, and a conclusion will be drawn in Section 5 .

\section{Data and Methods}

\subsection{Data}

\subsubsection{Typhoon Track Data and Basic Information}

The typhoon information used in this study, including the time, central location, maximum wind speed (MWS), central pressure, transnational speed, and seventh-level wind circle every $6 \mathrm{~h}$, was obtained from the Central Meteorological Observatory (http://typhoon.nmc.cn/web.html). The typhoons named LionRock and Megi in 2016 and Trami and KongRey in 2018 are discussed in this study. Information on the four typhoons is displayed in Table 1, while the tracks and intensities of these four typhoons are shown in Figure 1.

Table 1. Information about the four typhoons.

\begin{tabular}{ccccc}
\hline Name & Code No. & Duration (h) & Max Wind Speed (m/s) & Min Pressure (hPa) \\
\hline LionRock & 1610 & 276 & 50 & 935 \\
Megi & 1617 & 135 & 52 & 935 \\
Trami & 1824 & 222 & 60 & 920 \\
KongRey & 1825 & 180 & 60 & 920 \\
\hline
\end{tabular}

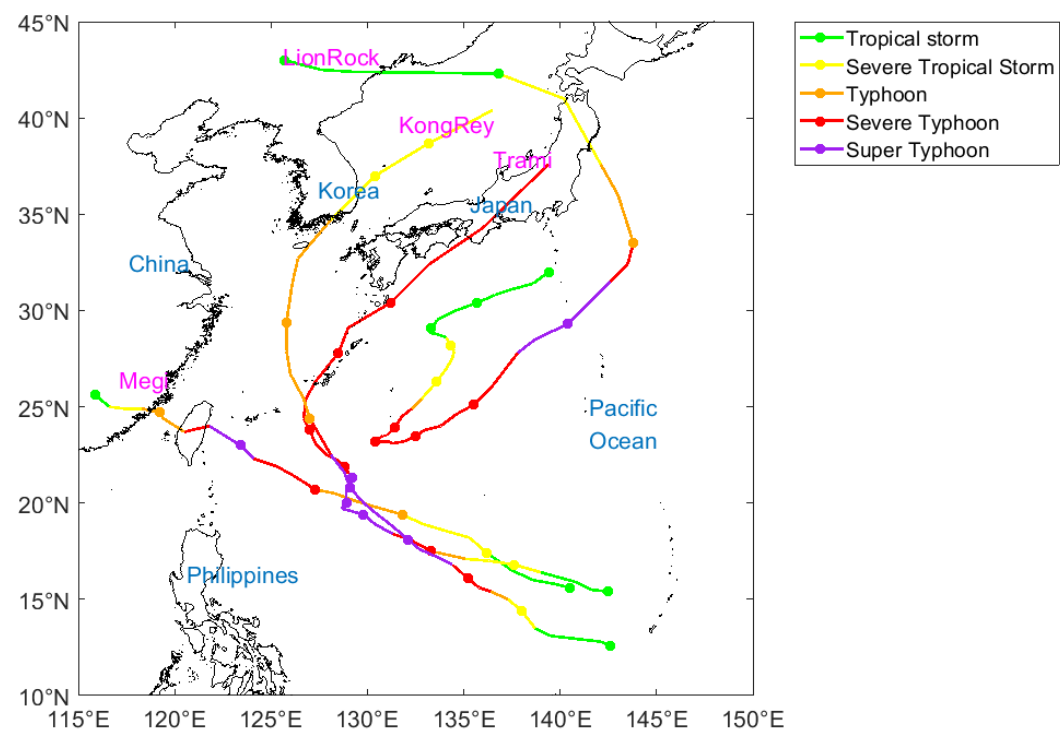

Figure 1. Path map of Typhoon LionRock (1610), Megi (1617), Trami (1824), and KongRey (1825). The colored dotted lines show the trajectories of the typhoons. The different colors represent the typhoon intensities set by the China Meteorological Administration. The time interval between the dots is $24 \mathrm{~h}$. 


\subsubsection{Satellite Observations}

The SST data used in this study are microwave and infrared OI SST (MW-IR OISST) data from the remote sensing system (http://data.remss.com/sst/daily/mw/v05.0/netcdf/) with a spatial resolution of $9 \mathrm{~km}$ and a time resolution of 1 day.

\subsection{Methods}

Here, we would like to introduce another GMR method differing from the LI method in some physical considerations. Firstly, for the reference temperature, the SST averaged over 5 days before the typhoon's arrival is suggested to smooth the possible influence of weather processes such as thunderstorms. This modification is expected to better represent the pre-existing sea surface status. Another reason is that pentad data are commonly used to index the monsoons (e.g., Xie et al., 1998 [38], Wang et al., 2004 [39]), and the influential time scale of a typhoon often exceed 5 days but is apparently shorter than that of the monsoons. Secondly, the minimum temperatures are taken from the arrival day of the typhoon to 5 days after its passage, since most of the significant cooling was found to happen during that period [25]. This thought is consistent with the LI method. Thirdly, only areas covered under the level-7 Beaufort scale (BS) wind-force will be counted, because it will be recognized as a storm only if the wind-force exceeds level-7 BS $(\sim 17.1 \mathrm{~m} / \mathrm{s})$.

For the first step, the average value of the four-direction level-7 BS wind-force diameter is calculated to identify the area to apply the current algorithm. The second step is to determine the time at which a point in the area is affected by the typhoon. For any point affected by the typhoon, we define the moment when the typhoon comes and the point is only affected by the typhoon (i.e., the moment when the typhoon level-7 BS wind-force begins to cover this point) as $t$ _s, and the moment when the typhoon passes and the point is no longer affected by the typhoon (i.e., the moment when the typhoon's level-7 BS wind-force leaves the point) as t_e.

The third step is to calculate the RT (SST_0) of a point before it is affected by the typhoon and the MT (SST_t) of the point during the influence of the typhoon. Referring to the experience of previous scholars, we assume that SST_0 is the average value of the SST 5 days before $t \_s$. That is,

$$
\mathrm{SST} \_0=\left(\mathrm{SST}_{\mathrm{t}_{\mathrm{s}-1}-1}+\mathrm{SST}_{\mathrm{t}_{\mathrm{s}-2}-2}+\mathrm{SST}_{\mathrm{t}_{\_} \mathrm{s}-3}+\mathrm{SST}_{\mathrm{t}_{\_} \mathrm{s}-4}+\mathrm{SST}_{\mathrm{t}_{\_} \mathrm{s}-5}\right) / 5
$$

Similarly, we define SST_0 as the minimum SST during $\mathrm{t} \_s$ and 5 days after $\mathrm{t} \_$e. That is,

$$
S S T \_t=\min \left(S_{-} T_{t_{\_}}, S S T_{t_{-} s+1}, \ldots, S S T_{t_{\_}}, \ldots, S S T_{t_{\_} e+5}\right)
$$

Then the magnitude of the SST drop caused by the typhoon is

$$
\mathrm{SSC}=\text { SST_t }- \text { SST_0 }
$$

For comparison, the former algorithms will be referred to as A1, A2, A3, and A4 (described in the Introduction). The algorithm proposed in this paper will be called CA. Only areas covered by the level-7 BS wind-force will be calculated except for the calculation area of A4 is $400 \mathrm{~km}$.

\section{Results}

\subsection{Megi}

Megi (1617) was generated at 8 o'clock on 23 September on the surface of the NWPO $2140 \mathrm{~km}$ southeast of Taiwan Province with an MWS of $18 \mathrm{~m} / \mathrm{s}$ and a center pressure of $998 \mathrm{hPa}$. In the early morning of 27 September, when its center was located at $22.4^{\circ} \mathrm{N}$ and $123.8^{\circ} \mathrm{E}$, it strengthened into a super typhoon. The MWS near the center was $52 \mathrm{~m} / \mathrm{s}$, the lowest center pressure was $935 \mathrm{hPa}$, and the radius of the seventh-level wind circle was 350 to $450 \mathrm{~km}$. On the same day, it made landfall in Hualian 
County, Taiwan Province, and weakened after that. Then it crossed the Taiwan Strait and made landfall again in Hui'an County, Fujian Province.

As shown in Figure 2, the respective ranges of SSC values caused by Megi when calculated using A1 through $\mathrm{A} 4$ are -2.16 to $0.5^{\circ} \mathrm{C},-3.8167$ to $1.0{ }^{\circ} \mathrm{C},-1.9029$ to $1.0{ }^{\circ} \mathrm{C}$, and -3.835 to $0{ }^{\circ} \mathrm{C}$, and that calculated using CA is -3.818 to $0^{\circ} \mathrm{C}$. Since the accuracy of the satellite-based SST data is around $0.5^{\circ} \mathrm{C}$, differential values between -1 and $1{ }^{\circ} \mathrm{C}$ are within the error range which could be ignored. What the five algorithms' results have in common is that the regions where the cooling is most distinct are all to the right of the typhoon's path. The cooling ranges of CA, A2 and A4 were the closest and the largest, and the cooling centers of them were the most similar, which were different from the other two. For A4, even though the calculated area is larger than the other four methods, it does not show more obvious cooling points. Compared to CA, A2 and A4, A1 and A3 underestimate the temperature drop by almost $2{ }^{\circ} \mathrm{C}$. In these two graphs, there was more than one maximum cooling center, and it appeared in different typhoon stages along the typhoon's path. This phenomenon is at odds with existing research and our perceptions. Both A1 and A3 assume that the SST drops only after the typhoon passes, but actually it begins to drop during the typhoon and the temperature of the affected sea area earlier is likely to have started to rise by the time the typhoon disappears. Therefore, the minimum temperature is omitted, resulting in the lower result of these two algorithms.
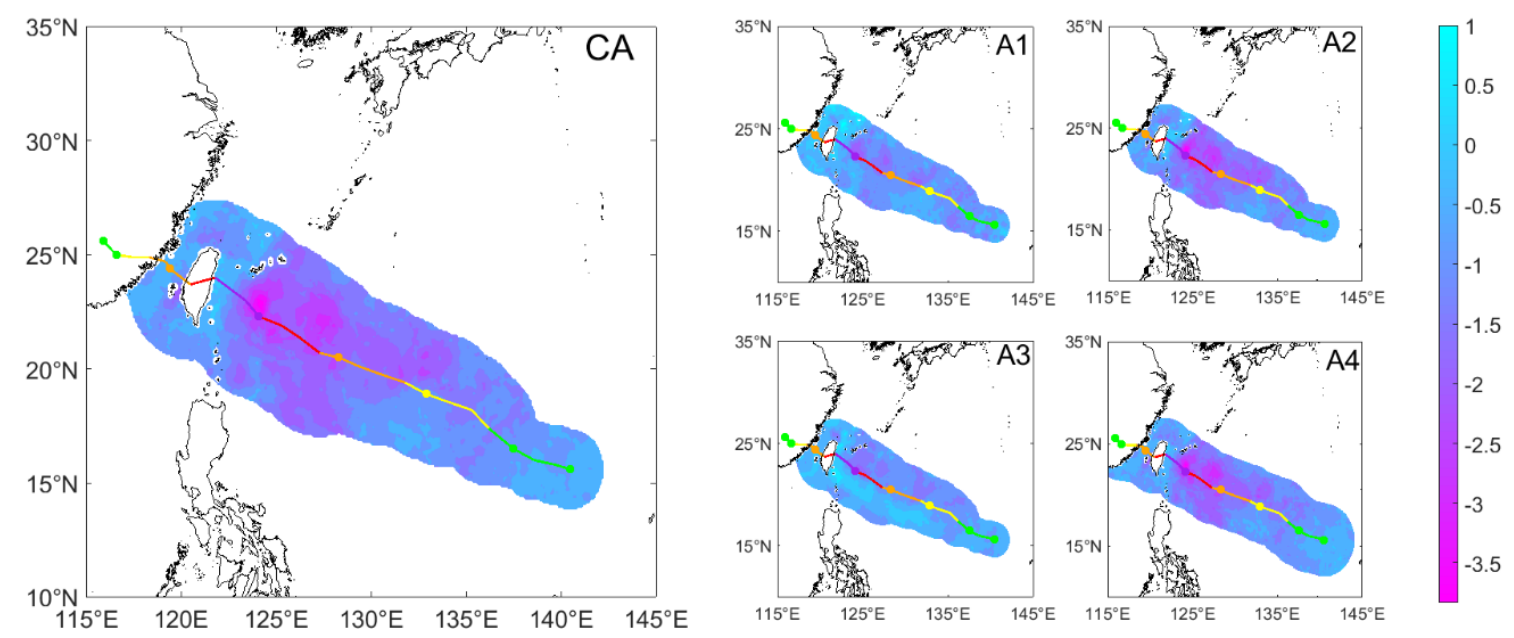

Figure 2. The sea surface cooling (SSC) results of Megi using A1, A2, A3, A4, and CA. The colored bar represents the cooling degrees in Celsius. The colors on the trajectory are consistent with those in Figure 1, showing the intensities of Megi.

\subsection{LionRock}

LionRock (1610) began with a low-pressure area that formed on the west of Wake Island on 15 August. On 25 August, LionRock sluggishly moved northwestward. Then a sudden turning occurred, and it moved to the north of Japan on the second day. On the afternoon of 28 August, LionRock developed into a super typhoon with an MWS of $52 \mathrm{~m} / \mathrm{s}$ and a center pressure of $935 \mathrm{hpa}$. At 5 p.m. on 30 August, it landed near Otsuto City, Iwate Prefecture, Japan. In the early morning of 31 August, it made landfall again near the city of Vladivostok in Russia's Primorsky Krai. The formation location of LionRock was at $33.1^{\circ} \mathrm{N}$, making it the most northern storm in the 21st century. The path of LionRock was too complicated to predict because it not only moved in a spiral shape over the southern edge of Japan but also crossed the eastern part of Honshu Island and entered the Sea of Japan.

The cooling ranges of LionRock obtained by using 5 algorithms are -6.16 to $3{ }^{\circ} \mathrm{C}$ (A1), -5.95 to $0{ }^{\circ} \mathrm{C}$ (A2), -4.3033 to $4.0^{\circ} \mathrm{C}$ (A3), -5.655 to $0{ }^{\circ} \mathrm{C}$ (A4), and -5.566 to $0{ }^{\circ} \mathrm{C}(\mathrm{CA})$ respectively, as shown in Figure 3. Although A1 has the greatest cooling among the five algorithms, the maximum cooling center appeared in the Sea of Japan when the typhoon weakened and was about to make landfall, which is inconsistent with theory and practice. In addition, abnormally positive values only appeared in A1 and 
A3. CA, A2 and A4 still give the most similar results, from which we can see more evidently that during the passage of LionRock, there was a cool tail along its path with a rightward bias. Moreover, the cooling was greatest at the turning point of the track or when the typhoon wind speed was relatively high, and the cooling areas around the turning point were concentrated in circular areas.
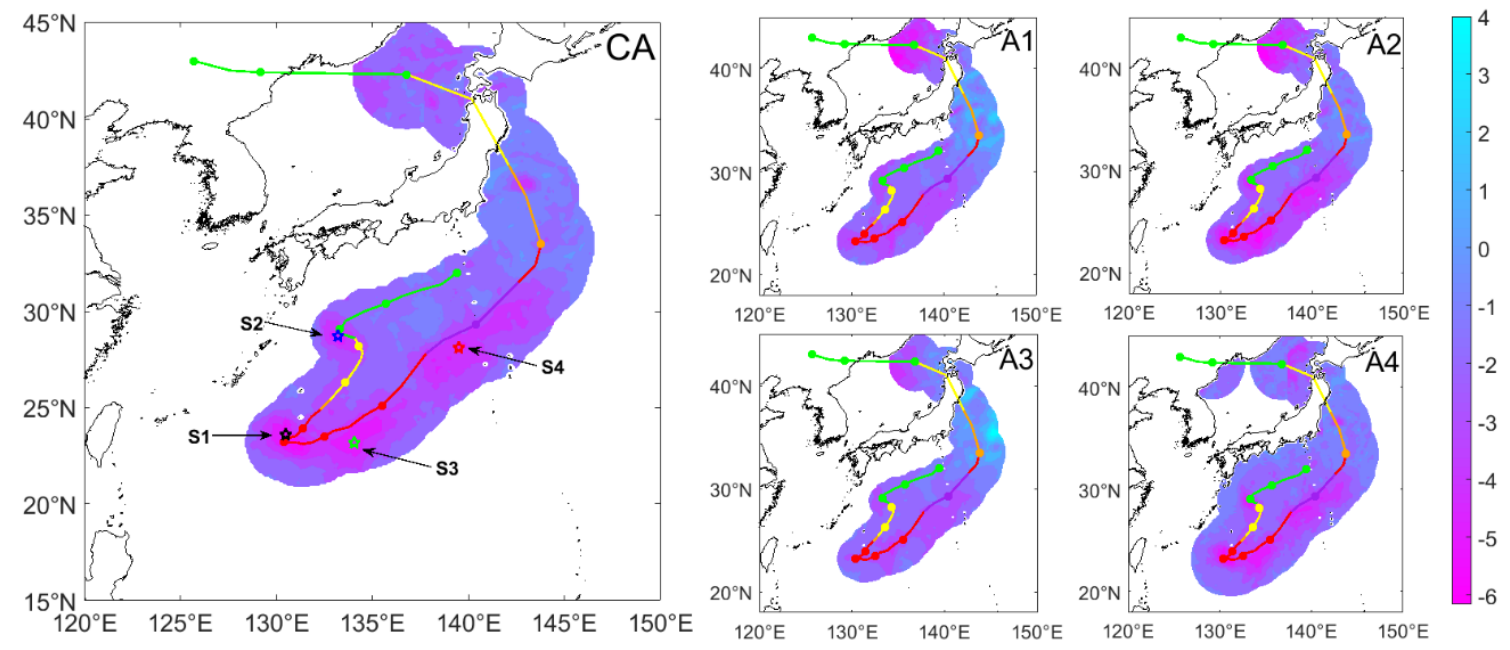

Figure 3. SSC result of LionRock using A1, A2, A3, A4, and CA. The colored bar represents the cooling degrees in Celsius. The colors on the trajectory are consistent with those in Figure 1, showing the intensities of LionRock.

In order to better observe SST variation near the turning points, the line diagram of daily temperature changes at four randomly selected points in this area is shown in Figure 4. From 21 to 23 August, S2 was affected by LionRock. The SST also suddenly dropped during this period, and the temperature began to rise slowly after a drop of up to $4.5^{\circ} \mathrm{C}$. S1 was covered by LionRock from 24 to 26 August with an SSC of $5.5^{\circ} \mathrm{C}$. During the period of 24 to 28 August, LionRock caused a SST drop of about $5{ }^{\circ} \mathrm{C}$ in S3. LionRock entered the area of the S4 on 27 August and left on 29 August, resulting in a SSC of about $3{ }^{\circ} \mathrm{C}$. The calculation results of the four points under the five algorithms are shown in Table 2. The data in the table show that the calculation result of $\mathrm{CA}, \mathrm{A} 2$ and $\mathrm{A} 4$ are very close and reasonable, while the results for $\mathrm{A} 1$ and $\mathrm{A} 3$ are about $2{ }^{\circ} \mathrm{C}$ lower than those in Figure 4 .

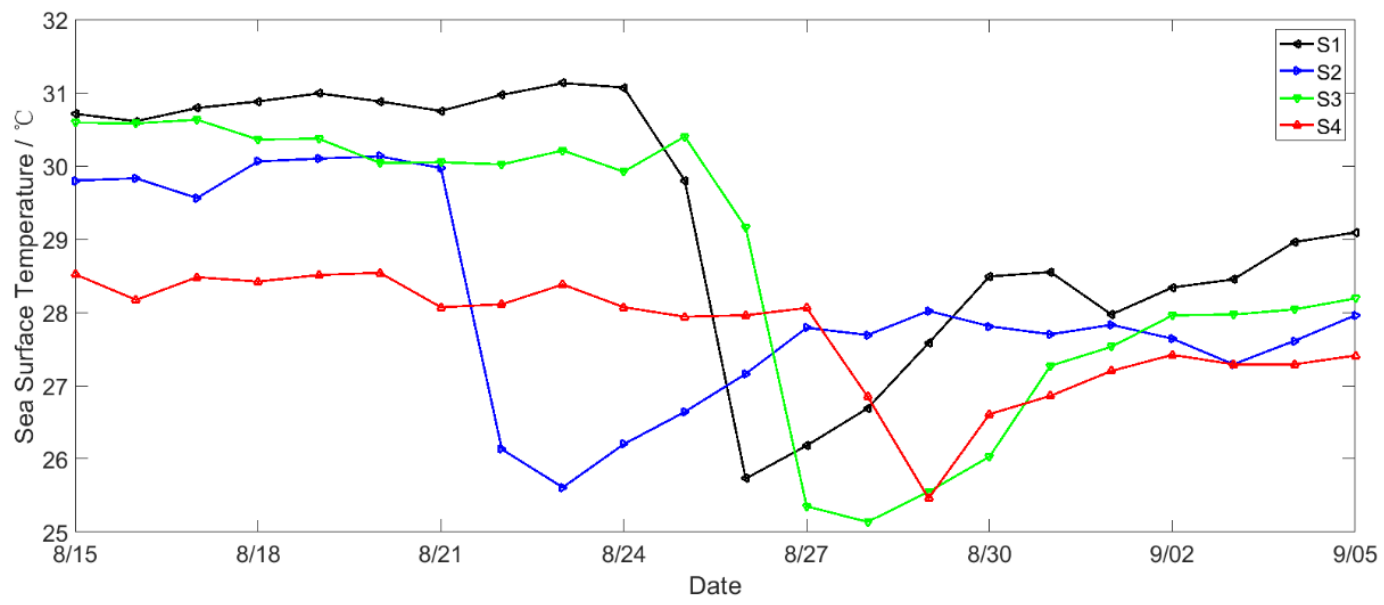

Figure 4. Daily sea surface temperature (SST) variation during the applying period of the current algorithm, at four selected points shown in Figure 3. 
Table 2. SSC in S1-S4 calculated by different methods.

\begin{tabular}{cccccc}
\hline Dots & $\mathbf{A} 1\left({ }^{\circ} \mathbf{C}\right)$ & $\mathbf{A} 2\left({ }^{\circ} \mathbf{C}\right)$ & $\mathbf{A} 3\left({ }^{\circ} \mathbf{C}\right)$ & $\mathbf{A 4}\left({ }^{\circ} \mathbf{C}\right)$ & CA $\left({ }^{\circ} \mathbf{C}\right)$ \\
\hline S1 & -3.11 & -4.58 & -2.02 & -4.69 & -4.59 \\
S2 & -2.40 & -4.22 & -2.27 & -4.43 & -4.25 \\
S3 & -2.76 & -5.02 & -2.50 & -4.81 & -4.80 \\
S4 & -1.25 & -3.07 & -1.21 & -2.70 & -2.78 \\
\hline
\end{tabular}

\subsection{Successive Typhoons: Trami and KongRey}

Trami (1824) formed in NWPO on 16 September. It moved steadily northwestward and developed into a super typhoon on 25 September. Then it slowed down and turned to move northeastward. Trami made landfall on the coast of Wakayama Prefecture, Honshu Island, Japan on 30 September with an MWS of $42 \mathrm{~m} / \mathrm{s}$ and a minimum center pressure of $952 \mathrm{hPa}$.

On 29 September, one day before Trami made landfall, KongRey developed into a tropical storm on the NWPO northeast of Pohnpei. After that, KongRey moved steadily northwestward, and the intensity gradually increased. KongRey followed Trami's track to the northwest and gradually intensified until it became a super typhoon at 5 p.m. on 1 October. It made landfall on the coast of South Gyeongsang Province in South Korea around 8:40 on 6 October, and the MWS at the center was $30 \mathrm{~m} / \mathrm{s}$. After that, its intensity continued to weaken. KongRey crossed the same ocean area to Trami so that part of the sea area was continuously affected by two typhoons.

As shown in Figure 5 (upper), the SSC ranges of Trami calculated by the five algorithms are: -5.2 to $0.5{ }^{\circ} \mathrm{C}$ (A1), -6.8367 to $0{ }^{\circ} \mathrm{C}$ (A2), -5.2119 to $0.6262{ }^{\circ} \mathrm{C}$ (A3), -6.94 to $0{ }^{\circ} \mathrm{C}$ (A4) and -6.932 to $0{ }^{\circ} \mathrm{C}$ (CA), respectively. The positive value of SSC less than $1^{\circ} \mathrm{C}$ is considered to be within the acceptable error range. As with the previous two typhoons, the results of A2, A4 and CA were the closest, and the maximum cooling areas were almost the same (i.e., it was on the right side of the typhoon path when the intensity was at a maximum). A1 and A3 significantly underestimated the cooling in degrees and showed smaller cooling areas.
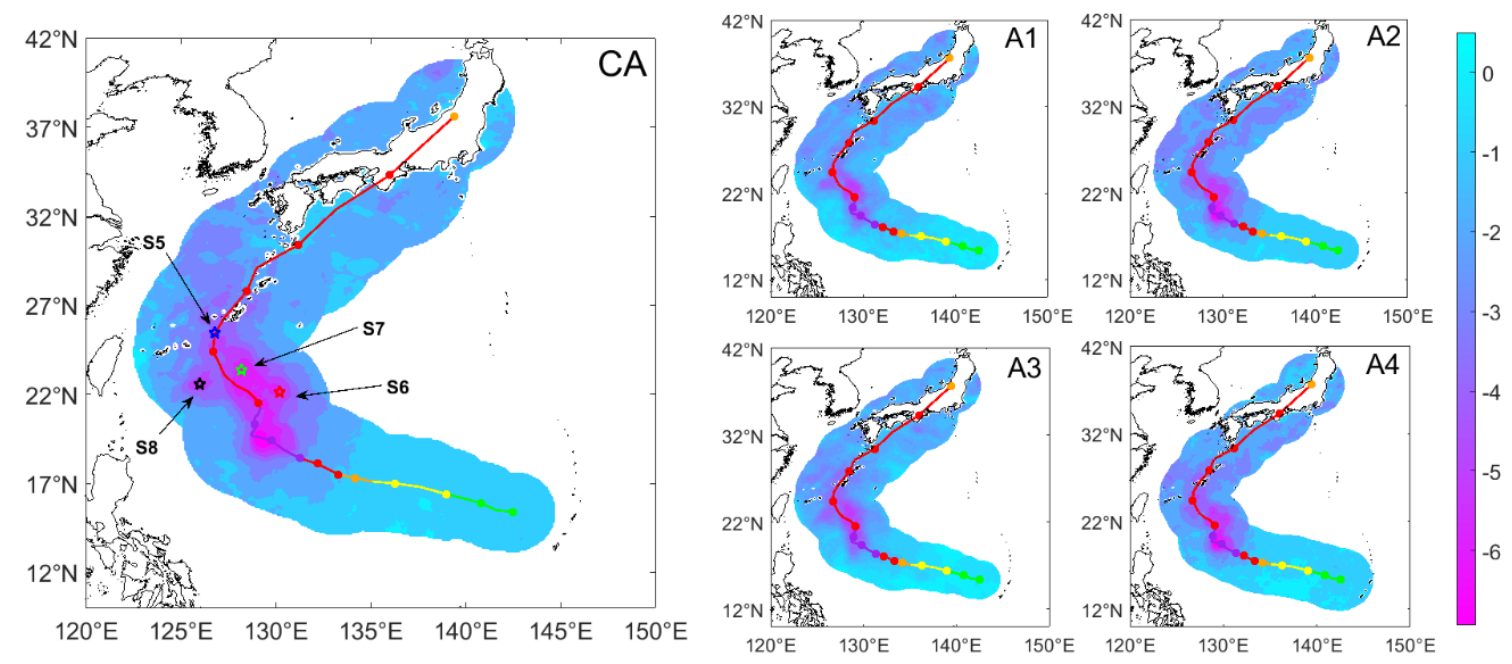

Figure 5. Cont. 

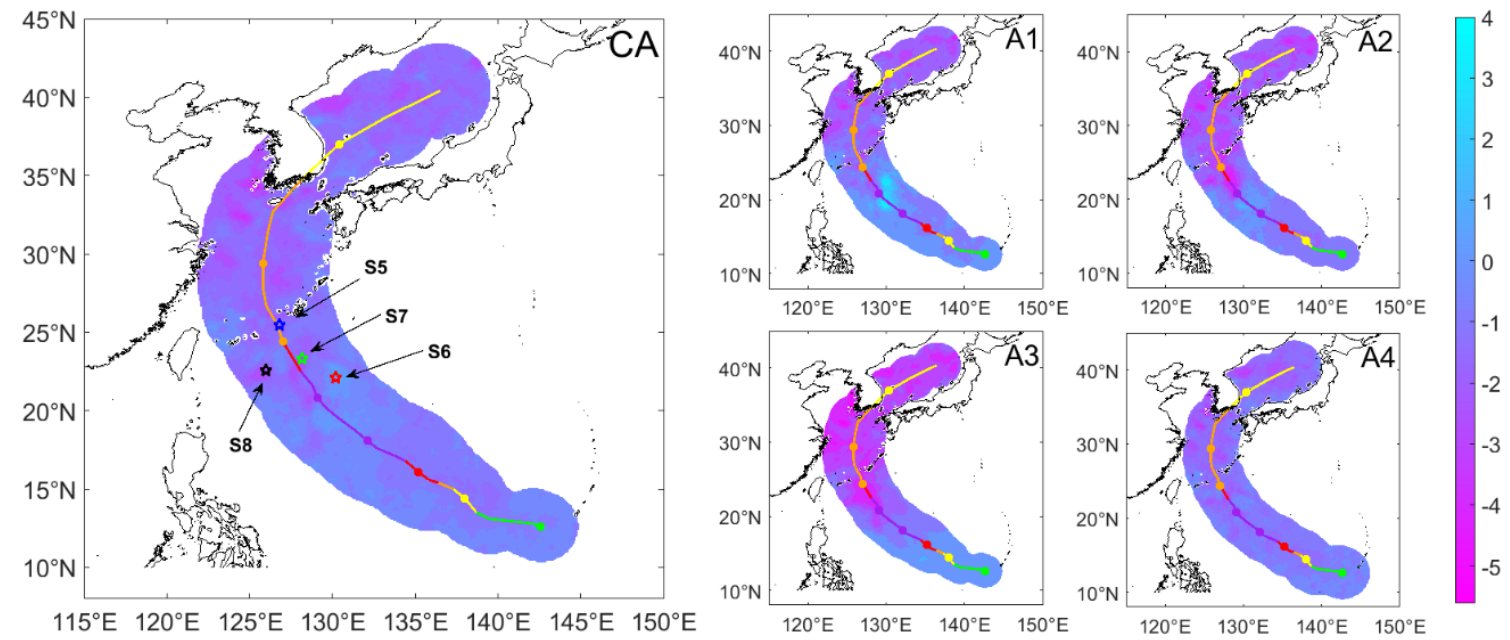

Figure 5. The SSC results of Trami (upper) and KongRey (bottom) using A1, A2, A3, A4, and CA. The colored bar represents the cooling degrees in Celsius. The colors on the trajectory are consistent with those in Figure 1, showing the intensities of the typhoons.

The SSC ranges for KongRey, as obtained by five algorithms respectively, are -4.38 to $4.0^{\circ} \mathrm{C}$ (A1), -4.5333 to $2.0^{\circ} \mathrm{C}$ (A2), -5.6157 to $1.0^{\circ} \mathrm{C}$ (A3), -4.245 to $-0.5^{\circ} \mathrm{C}$ (A4), and -4.468 to $1.0{ }^{\circ} \mathrm{C}$ (CA). As Figure 5 (bottom) shows, the distribution of SSC caused by KongRey has no obvious characteristics, and no obvious cooling center can be found in the five pictures. What is worth noting is that the sea surface warming occurred when KongRey developed into a super typhoon. This might be because the pre-existing SSTs were still in a cold status influenced by the previous typhoon, Trami, which may have reduced the heat-flux during the passage of typhoon KongRey.

Considering that Typhoon KongRey once again affected part of the sea area where Trami passed, four points were selected from the sea area under the continuous influence of Trami and KongRey. The variations of daily SST at these points are shown in Figure 6. Trami and KongRey passed through the area from 25 to 29 September and from 3 to 5 October, respectively, so the temperature at the 4 points cooled down twice. The first cooling occurred from 24 to 29 September. In this process, the SST of S5, S6, S7 and S8 decreased by about $3,5,3.5$, and $2{ }^{\circ} \mathrm{C}$, respectively, which should be the result caused by Trami. The second SSC occurring between 1 and 4 October should be the result of KongRey's influence. In this process, the SST at S7 declined the most significantly by about $4{ }^{\circ} \mathrm{C}$, followed by S8, by about $3^{\circ} \mathrm{C}$, S5 by slightly more than $1^{\circ} \mathrm{C}$ and $\mathrm{S} 6$ by less than $1^{\circ} \mathrm{C}$.

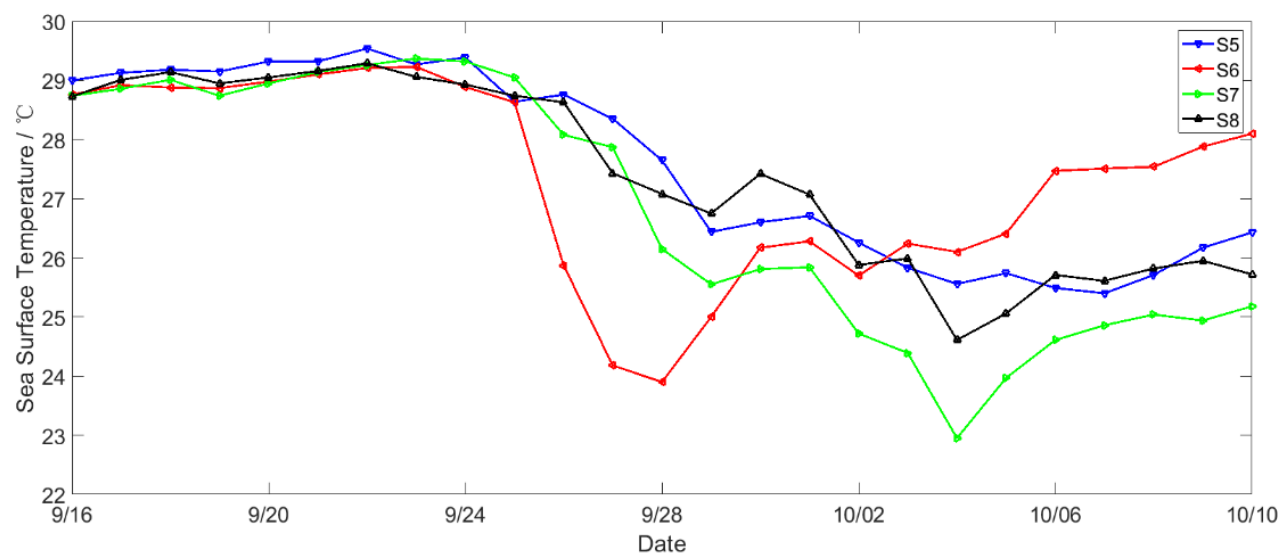

Figure 6. Daily SST variation during the applying period of the current algorithm, at four selected points shown in Figure 5. 


\section{Discussion}

The SSC ranges calculated by all the algorithms are listed in Table 3. It is clearly that A2, A4, and CA approached similar results. This is because all of them are essentially maximum response methods. Slight divergences come from the choices of the MT and the RT.

Table 3. The SSC ranges of the four typhoons calculated by different algorithms.

\begin{tabular}{cccccc}
\hline Name & $\mathbf{A 1}\left({ }^{\circ} \mathbf{C}\right)$ & $\mathbf{A} 2\left({ }^{\circ} \mathbf{C}\right)$ & $\mathbf{A} 3\left({ }^{\circ} \mathbf{C}\right)$ & $\mathbf{A 4}\left({ }^{\circ} \mathbf{C}\right)$ & CA $\left({ }^{\circ} \mathbf{C}\right)$ \\
\hline Megi & $-2.16-1$ & $-3.82-0.5$ & $-1.90-1$ & $-3.84 \sim 0$ & $-3.82-0$ \\
LionRock & $-6.16-3$ & $-5.95-0$ & $-4.30-4$ & $-5.66-0$ & $-5.57-0$ \\
Trami & $-5.2-0.5$ & $-6.84-0$ & $-5.21-0.63$ & $-6.94-0$ & $-6.93-0$ \\
KongRey & $-4.38-4$ & $-4.53-2$ & $-5.62-1$ & $-4.25--0.5$ & $-4.47-1$ \\
\hline
\end{tabular}

Although A1 and A3 seem to have generally underestimated the SSC degrees, one minimum was captured by A1 in the LionRock case and another was captured by A3 in the KongRey case. Since the MT defined in A1 will also be considered in other algorithms except for A3, it is reasonable to assume that A1 will take some higher RT values into calculation. The idea of calculating the day-to-day differences brings abnormally positive results. The same situation happens in A3, which calculates the mean-to-mean differences. In the KongRey case, the minimum in A3 might come from a higher RT because it takes the SST averaged over 10 to 3 days before the arrival of the typhoon. It covered a period even before the prior typhoon, Trami.

Comparing this to A4 and CA, ignoring the possibility that the maximum response may happen after the typhoon's passage might be the main problem of A2. To prove this, the days from the typhoon's leaving date to when the MT was captured have been countered at each grid and shown in Figure 7. This shows that in a fairly large area, strongest cooling occurred within 1 to 5 days after the typhoon left. Situations were more obvious in the downstream area of the successive typhoons, Trami and KongRey.

(a) Megi

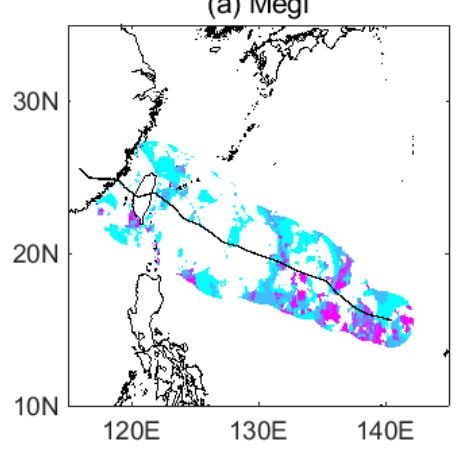

(c) Trami

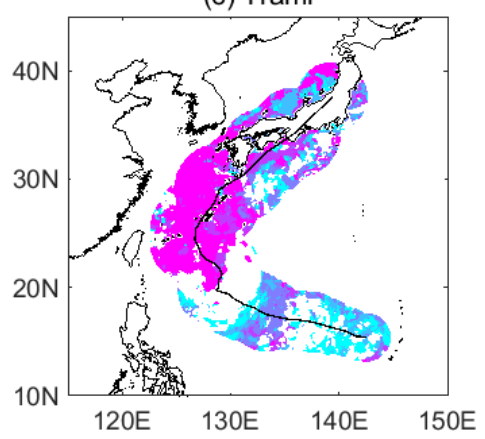

(b) LionRock

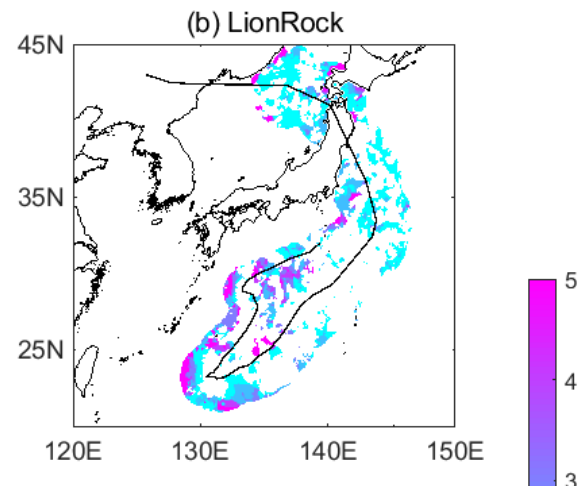

(d) KongRey

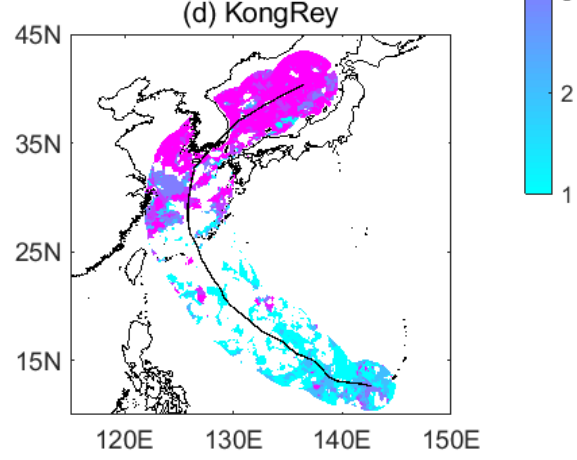

Figure 7. The days from the time typhoon leaving to the time when the minimum temperature (MT) occurred. The different colors represent different days. 
The algorithm proposed here (CA) has a lot in common with the LI method (A4). Those differing from the others are both grid-based, which may improve the results in slow-moving typhoon cases. If we treat the typhoon's lifetime as the forcing time, applying it to every grid in the whole domain (non-grid-based), wrong MTs might be chosen in the upstream area while wrong RTs might be counted in the downstream area. This situation happened in the case of LionRock, which moved very slowly around the southwestern tip of its path and turned almost totally to move northeastward [18]. In Figure 3, both A1 and A3 showed abnormal surface warming results in the downstream area, while both A1 and A2 calculated significant cooling in the Sea of Japan that is not shown in CA and A4. A cooling center located around $\left(36^{\circ} \mathrm{N}, 144^{\circ} \mathrm{E}\right)$ on the path was detected by $\mathrm{CA}$ and $\mathrm{A} 4$, but it was not shown in the result of A2.

The major divergence between CA and A4 is the definition of RT before the typhoon's arrival and the slight differences laid in the KongRey case (Figure 5), while CA calculated a surface warming around S6, but this was not shown in the result of A4. From Figure 6, it is clear that the SST around S6 was in a continuous recovery from the significant influence of the prior typhoon, Trami, during the typhoon KongRey's forcing time. Therefore, a surface warming result seems to be reasonable. Then the pentad mean RT is argued to be more representative of the pre-existing sea surface status than the 2 day average which was applied in A4.

Another slight difference is that CA calculates the SSC in the area covered under the level-7 BS wind-force, while A4 estimates the SSC in the area less than $400 \mathrm{~km}$ away from the path. This brings hardly any difference in the results, except that the changing shapes of the affected area in the CA results seem to be consistent with the evolution of the typhoons, which makes the results much livelier.

\section{Conclusions}

A new algorithm (CA) to estimate the sea surface cooling caused by typhoons has been proposed based upon the grid-based maximum response method suggested by Li et al. [33]. It differs from the LI method by defining the reference temperature as the pentad mean SST before the typhoon, and counting the area covered under the level-7 BS wind-force instead of that within a radius of $400 \mathrm{~km}$. The MW-IR OISST dataset was used to calculate the SSC caused by four typhoon cases, Megi, LionRock, Trami, and KongRey. The results of different algorithms were compared to valid the improvement of CA.

In all the four cases, maximum response methods (CA, A2, and A4) produced similar results, while A1 and A3 seem to underestimate the SSC in degrees. In the LionRock case, grid-based methods (CA and A4) showed improvement to solve the slow-moving problems. Meanwhile, in the successive typhoon cases, Trami and KongRey, the results of CA seem to have reasonably detected some surface warming, showing an improvement in representing the pre-existing sea surface status before the typhoon's arrival by applying the pentad mean SST as reference. The slight change in using level-7 BS wind-force coverage brings nothing but livelier results.

Although the performance of CA will still be questionable when the interval between successive typhoons is less than 5 days, there were only nine such cases during the past 6 years (2014-2019). Therefore, the algorithm has been validated in general and should be recommended for use in future research.

Author Contributions: Conceptualization, D.S.; Methodology, D.S. and L.X.; Software, L.X. and L.G.; Validation, D.S., L.X. and L.G.; Formal Analysis, B.L.; Investigation, B.L.; Resources, L.X. and B.L.; Data Curation, L.G. and B.L.; Writing-Original Draft, L.X.; Writing-Review and Editing, D.S. and B.L.; Visualization, L.X. and L.G.; Supervision, D.S.; Project Administration, D.S.; Funding Acquisition, D.S. and B.L. All authors have read and agreed to the published version of the manuscript.

Funding: This research was funded by the Zhejiang Provincial Natural Science Foundation of China under grant number LY17D060003, the Bureau of Science and Technology of Zhoushan under grant number 2018C81032, the National Natural Science Foundation of China under grant number 41706022 and 41830533, and the Key Laboratory of Ocean Circulation and Waves of the Chinese Academy of Sciences under grant number KLOCW1704. 
Acknowledgments: We would like to thank Jinsong Yang, Shuangyan He, Jiawang Chen and some other colleagues for their remarkable advice on the present work. We also deeply thank all the reviewers for their valuable comments and discussions.

Conflicts of Interest: The authors declare no conflict of interest. The founding sponsors had no role in the design of the study; in the collection, analyses, or interpretation of data; in the writing of the manuscript, and in the decision to publish the results.

\section{References}

1. Chen, Z.W.; Kang, J.C.; Gu, C.L.; Xu, Y.; Tang, M.; Lu, K. Variation characteristics of the extreme sea surface temperature events in the Northwest Pacific and its relationship with ENSO over the past 33 Years. Mar. Environ. Sci. 2019, 38, 221-232. (In Chinese)

2. Yuan, F.C.; Chen, M.N.; Chen, D.W. Changes of tropical cyclones in China and Fujian over the past 60 years. Mar. Forecast 2010, 27, 34-39. (In Chinese) [CrossRef]

3. Hu, Y.M.; Song, L.L.; Liu, A.J.; Pan, W.J. Analysis of the climatic features of landfall tropical cyclones in China during the past 58 years. Zhongshan Daxue Xuebao/Acta Sci. Nat. Univ. Sunyatseni 2008, 47, 115-121. [CrossRef]

4. Zhou, L.; Chen, D.K.; Lei, X.T.; Wang, W.; Wang, G.H.; Han, G.J. Progress and perspective on interactions between ocean and typhoon. Chin. Sci. Bull. 2018, 64, 60-72. (In Chinese) [CrossRef]

5. Price, J.F. Upper ocean response to a hurricane. J. Phys. Oceanogr. 1981, 11, 153-175. [CrossRef]

6. Yin, X.B.; Wang, Z.Z.; Liu, Y.G.; Xu, Y. Ocean response to Typhoon Ketsana traveling over the northwest Pacific and a numerical model approach. Geophys. Res. Lett. 2007, 34, 21606. [CrossRef]

7. Yang, L.Q. Responses to 2012 Typhoon Tembin in terms of near-surface flow and thermohaline. J. Trop. Oceanogr. 2015, 3, 13-22. (In Chinese) [CrossRef]

8. Lei, F.M.; Jiang, Y.W. Mechanism of the Ocean Water Cooling Caused by Typhoon Sinlaku in 2008. J. Xiamen Univ. 2012, 51, 903-910. [CrossRef]

9. Sun, L.; Yang, Y.-J.; Xian, T.; Lu, Z.; Fu, Y.-F. Strong enhancement of chlorophyll a concentration by a weak typhoon. Mar. Ecol. Prog. Ser. 2010, 404, 39-50. [CrossRef]

10. Black, W.J.; Dickey, T.D. Observations and analyses of upper ocean responses to tropical storms and hurricanes in the vicinity of Bermuda. J. Geophys. Res. Oceans 2008, 113, 9. [CrossRef]

11. Shang, S.L.; Li, L.; Sun, F.Q.; Wu, J.Y.; Hu, C.M.; Chen, D.W.; Ning, X.R.; Qiu, Y.; Zhang, C.Y.; Shang, S.P. Changes of temperature and bio-optical properties in the South China Sea in response to Typhoon Lingling, 2001. Geophys. Res. Lett. 2008, 35, L10602. [CrossRef]

12. Lin, I.; Liu, W.T.; Wu, C.C.; Wong, G.T.F.; Hu, C.; Chen, Z.; Liang, W.D.; Yang, Y.; Liu, K.K. New evidence for enhanced primary production triggered by tropical cyclone. Geophys. Res. Lett. 2003, 30, 1718. [CrossRef]

13. Mou, P.Y.; Lin, X.P. Changes in Upper Ocean Temperature, Salt and Sea level During Typhoon SOULIK (2013). Trans. Oceanol. Limnol. 2018, 3,1-11. (In Chinese)

14. Dare, R.A.; Mcbride, J.L. Sea surface temperature response to tropical cyclones. Mon. Weather Rev. 2011, 139, 3798-3808. [CrossRef]

15. Xu, W.L. The Impact of Typhoon on sea Surface Temperature; Ocean University of China: Qingdao, China, 2007. [CrossRef]

16. Liang, P.; Guan, S.D.; Zhao, W.; Zhang, J. Influence of tropical cyclones parameters on the sea surface temperature cooling. J. Ocean Univ. China 2014, 44, 11-17.

17. Sun, L.; Wang, D.X.; Hu, J.Y.; Gao, R.Z. Responses of upper layer of the Northern South China Sea to two locally-generated tropical cyclones. J. Trop. Oceanogr. 2008, 27, 10-18.

18. Song, D.; Guo, L.; Duan, Z.; Xiang, L. Impact of Major Typhoons in 2016 on Sea Surface Features in the Northwestern Pacific. Water 2018, 10, 1326. [CrossRef]

19. Price, J.F.; Sanford, T.B.; Forristall, G.Z. Forced stage response to a moving hurricane. J. Phys. Oceanogr. 1994, 24, 233-260. [CrossRef]

20. Shay, L.K.; Black, P.G.; Mariano, A.J.; Hawkins, J.D.; Elsberry, R.L. Upper ocean response to Hurricane Gilbert. J. Geophys. Res. 1992, 97, 20227. [CrossRef]

21. D'Asaro, E.A.; Black, P.G.; Centurioni, L.R.; Chang, Y.T.; Chen, S.S.; Foster, R.C.; Graber, H.C.; Harr, P.; Hormann, V.; Lien, R.C.; et al. Impact of typhoons on the ocean in the Pacific. Bull. Am. Meteorol. Soc. 2014, 95, 1405-1418. [CrossRef] 
22. Vidya, P.J.; Das, S.; Mani, M.R. Contrasting Chl-a responses to the tropical cyclones Thane and Phailin in the Bay of Bengal. J. Mar. Syst. 2017, 165, 103-114. [CrossRef]

23. Wang, X.D.; Han, G.L.; Qi, Y.Q.; Li, W. Impact of barrier layer on typhoon-induced sea surface cooling. Dyn. Atmos. Oceans 2011, 52, 367-385. [CrossRef]

24. Xu, W.L.; Su, J. The impact of typhoons on sea surface temperature in the Western North Pacific Ocean. Period. Ocean Univ. China 2007, 37, 17-22. (In Chinese)

25. Liu, Z.H.; Xu, J.P.; Zhu, B.K.; Sun, C.H.; Zhang, L.F. Upper ocean response to tropical cyclones in northwestern Pacific during 2001-2004 by Argo data. J. Trop. Oceanoraphy 2006, 25, 1-8. (In Chinese) [CrossRef]

26. Park, J.J.; Young, O.K.; Price, J.F. Argo array observation of ocean heat content changes induced by tropical cyclones in the north Pacific. J. Geophys. Res. Oceans 2011, 116, C12025. [CrossRef]

27. Wang, G.H.; Wu, L.W.; Johnson, N.C.; Ling, Z. Observed three-dimensional structure of ocean cooling induced by Pacific tropical cyclones. Geophys. Res. Lett. 2016, 43, 7632-7638. [CrossRef]

28. Zhang, J.S.; Lin, Y.L.; Chavas, D.R.; Mei, W. Tropical cyclone cold wake size and its applications to power dissipation and ocean heat uptake estimates. Geophys. Res. Lett. 2019, 46, 10-177. [CrossRef]

29. Jiang, X.P.; Liu, C.X.; Qi, Y.Q. The Simulation of Typhoon Krovanh Using a Coupled Air-Sea Mode. Chin. J. Atmos. Sci. 2009, 33, 99-108. [CrossRef]

30. Shay, L.K.; Goni, G.L.; Black, P.G. Effects of a warm oceanic feature on Hurricane Opal. Mon. Weather Rev. 2000, 128, 1366-1383. [CrossRef]

31. Yang, J.Y.; Chang, M.H.; Hsieh, C.Y.; Chang, H.I.; Jan, S.; Wei, C.L. The role of enhanced velocity shears in rapid ocean cooling during Super Typhoon Nepartak 2016. Nat. Commun. 2019, 10, 1-11. [CrossRef] [PubMed]

32. Wang, L.Y.; Yu, C.C.; Wu, K.J. Response of Sea Surface Temperature to Typhoon in South China Sea. Trans. Oceanol. Limnol. 2017, 6, 67-74. (In Chinese)

33. Li, J.; Sun, L.; Yang, Y.; Cheng, H. Accurate Evaluation of Sea Surface Temperature Cooling Induced by Typhoons Based on Satellite Remote Sensing Observations. Water 2020, 12, 1413. [CrossRef]

34. Vincent, E.M.; Lengaigne, M.; Madec, G.; Vialard, J.; Samson, G.; Jourdain, N.C.; Menkes, C.E.; Jullien, S. Processes setting the characteristics of sea surface cooling induced by tropical cyclones. J. Geophys. Res. Atmos. 2012, 117, C02020. [CrossRef]

35. Pei, Y.H.; Zhang, R.H.; Chen, D.K. Upper ocean response to tropical cyclone wind forcing: A case study of typhoon Rammasun (2008). Sci. China 2015, 58, 1623-1632. [CrossRef]

36. Kashem, M.; Ahmed, M.K. The response of the upper ocean to tropical cyclone Viyaru over the Bay of Bengal. Acta Oceanol. Sin. 2019, 38, 61-70. [CrossRef]

37. Ning, J.; Xu, Q.; Feng, T.; Zhang, H. Upper Ocean Response to Two Sequential Tropical Cyclones over the Northwestern Pacific Ocean. Remote Sens. 2019, 11, 2431. [CrossRef]

38. Xie, A.; Chung, Y.; Liu, X.; Ye, Q. The Interannual Variations of the Summer Monsoon Onset over the South China Sea. Theor. Appl. Climatol. 1998, 59, 201-213. [CrossRef]

39. Wang, B.; Ho, L.; Zhang, Y.; Lu, M.M. Definition of South China Sea Monsoon Onset and Commencement of the East Asia Summer Monsoon. J. Clim. 2004, 17, 699-710. [CrossRef]

Publisher's Note: MDPI stays neutral with regard to jurisdictional claims in published maps and institutional affiliations.

(C) 2020 by the authors. Licensee MDPI, Basel, Switzerland. This article is an open access article distributed under the terms and conditions of the Creative Commons Attribution (CC BY) license (http://creativecommons.org/licenses/by/4.0/). 